Société d'histoire de la révolution de 1848 et des révolutions du XIXe siècle

$59 \mid 2019$

Souverainetés africaines

\title{
Fabio D'ANGELO, Dal Regno di Napoli alla Francia. Viaggi ed esilio tra Sette e Ottocento, préface de Gilles Bertrand
}

Grégoire Bron

\section{CpenEdition \\ Journals}

Édition électronique

URL : https://journals.openedition.org/rh19/6667

ISSN : 1777-5329

Éditeur

La Société de 1848

Édition imprimée

Date de publication : 30 décembre 2019

Pagination : 225-227

ISSN : 1265-1354

Référence électronique

Grégoire Bron, «Fabio D'ANGELO, Dal Regno di Napoli alla Francia. Viaggi ed esilio tra Sette e Ottocento, préface de Gilles Bertrand », Revue d'histoire du XIXe siècle [En ligne], 59 | 2019, mis en ligne le 11 janvier 2020, consulté le 03 janvier 2023. URL : http://journals.openedition.org/rh19/6667

Ce document a été généré automatiquement le 3 janvier 2023

Tous droits réservés 


\title{
Fabio D’ANGELO, Dal Regno di Napoli alla Francia. Viaggi ed esilio tra Sette e Ottocento, préface de Gilles Bertrand
}

\author{
Grégoire Bron
}

\section{RÉFÉRENCE}

Fabio D'ANGELO, Dal Regno di Napoli alla Francia. Viaggi ed esilio tra Sette e Ottocento, préface de Gilles Bertrand, Naples, Libreria Dante \& Descartes, 2018, 300 p., 20 euros.

1 Le beau livre, tiré de sa thèse de doctorat, que Fabio D'Angelo consacre aux voyages et à l'exil politique de savants napolitains en France, entre la fin du XVIII ${ }^{\mathrm{e}}$ siècle et le début $\mathrm{du} \mathrm{XIX}^{\mathrm{e}}$ siècle, vise à étudier les transferts scientifiques et techniques dont ils sont les vecteurs. En s'inspirant de la riche bibliographie récente qui souligne l'importance des différentes formes de mobilité du point de vue de la diffusion transnationale des savoirs et des idées, l'auteur souligne l'importance des relations entre le royaume de Naples et la France pour la participation du Mezzogiorno italien aux débats scientifiques contemporains. L'auteur développe sa réflexion à partir de la reconstitution minutieuse des biographies des différents ingénieurs, médecins, botanistes, minéralogistes, chimistes ou mathématiciens napolitains qui ont séjourné en France entre la fin des années 1780 et les années 1820.

2 En raison de cette approche biographique, le premier chapitre porte sur l'arrivée à Naples des jeunes étudiants de province qui, dans la capitale du royaume, fréquentent des institutions d'enseignement supérieur déjà bien intégrées aux réseaux internationaux du savoir. L'intérêt qui y est porté à l'innovation scientifique et technique, tout particulièrement à l'hôpital des Incurables où l'on s'intéresse, par exemple, aux théories de Lavoisier en chimie, ou de Brown en médecine, favorise également une réflexion politique critique, typique des Lumières. C'est néanmoins la confrontation directe de ces savants avec le débat intellectuel français qui constitue le 
cœur du propos. Elle est d'abord abordée, dans le deuxième chapitre, par l'examen des missions de formation ou de perfectionnement, financées par la couronne napolitaine, désireuse de tirer avantage des progrès techniques et scientifiques pour moderniser son État et ses institutions de recherche. Puis, dans le troisième chapitre, l'auteur étudie l'impact de l'exil en France sur l'évolution de la pensée et des pratiques scientifiques et intellectuelles des savants qui y ont trouvé asile après avoir été compromis lors de la brève expérience républicaine napolitaine de 1799.

Dans un cas comme dans l'autre, l'acquisition de nouvelles connaissances et compétences techniques et scientifiques à l'étranger s'inscrit dans une perspective patriotique, puisqu'elle est destinée à contribuer au développement et au progrès de l'État napolitain. Aussi l'auteur se penche-t-il, dans le cinquième chapitre, sur le retour - quand il a lieu - de ce personnel qualifié dans sa patrie d'origine et sur les conditions de son insertion dans les institutions du royaume. Enfin, pour compléter l'étude des transferts scientifiques et techniques franco-napolitains entre la fin du xvIII ${ }^{e}$ siècle et le début $d u$ XIX ${ }^{e}$ siècle, les cinquième et sixième chapitres sont consacrés à la circulation des publications et des instruments scientifiques entre les deux pays.

La recherche de Fabio D'Angelo se fonde sur des sources consultées dans de nombreuses archives et bibliothèques, tant en France qu'à Naples, dont la multiplicité et la richesse forcent l'admiration et assurent la grande qualité de l'ouvrage. Léger revers de la médaille cependant, l'auteur semble ne pas s'être résolu à abandonner une partie du matériau réuni lors de ses dépouillements, ce qui dessert quelque peu la cohérence du livre. Les deux derniers chapitres, intéressants en eux-mêmes, auraient ainsi probablement pu être publiés sous forme d'articles séparés. On pardonnera cependant aisément ce petit défaut, tant l'érudition qui émerge de la consultation intensive des archives offre des informations précieuses et précisément référencées à divers points de vue. Les spécialistes de la mobilité trouveront d'utiles renseignements sur les pratiques et les modalités du voyage scientifique, tirées des archives diplomatiques notamment; ceux de l'exil profiteront de l'analyse de la sociabilité de ces savants émigrés en France, recueillie dans les archives de police; ceux de la société napolitaine pourront y puiser de riches informations sur la politique et les institutions scientifiques du royaume des Deux-Siciles.

5 Cependant, c'est du point de vue de l'histoire des sciences que l'apport de l'ouvrage est le plus important. En examinant les rapports envoyés par ces savants aux autorités pour le compte desquelles ils voyagent, leurs documents personnels (journaux, notes, travaux manuscrits, correspondance) et leurs publications spécialisées, l'auteur présente minutieusement en quoi la fréquentation du monde scientifique français modifie les idées et les méthodes scientifiques de ces savants émigrés. Mais cette évolution réelle, précisément documentée, ne trouve qu'une application partielle à Naples, après le retour de ces savants dans leur pays. À partir de 1806, plusieurs d'entre eux y sont rappelés par les autorités napoléoniennes, qui souhaitent mettre à profit leurs compétences pour le développement scientifique de leur nouvel État et les nomment dans les différentes institutions culturelles du royaume. Bien qu'à la Restauration, ces savants conservent leur poste, les suspicions politiques dont ils font l'objet et les rivalités académiques qu'ils suscitent, puis, pour certains, l'adhésion au régime constitutionnel de 1820 , conduisent souvent à leur marginalisation et à leur isolement, ce qui ne les empêche nullement de poursuivre leurs recherches et leurs publications. La conclusion s'impose alors : si le séjour français des savants napolitains 
contribue de façon déterminante au renouvellement intellectuel des sciences napolitaines, il n'entraîne pas de réelles modernisations des institutions et des pratiques scientifiques napolitaines dominantes, encore caractérisées par la tradition.

6 Déployant une vaste érudition mais défendant une thèse forte, cet ouvrage, en adoptant une perspective transnationale dont il confirme la fécondité historiographique, apporte une importante contribution à l'histoire des sciences napolitaines entre les XVIII ${ }^{e}$ et XIX ${ }^{e}$ siècles. 